\title{
Conexões
}

Educação Física, Esporte e Saúde

\section{"Agora é a minha vez de jogar"? Percepção de estudantes sobre a utilização de Exergames na Educação Física Escolar}

\author{
Gustavo da Silva Freitas ${ }^{1}$ \\ Vinícius Behling da Silva² \\ Cesar Augusto Otero Vaghetti ${ }^{3}$
}

\section{RESUMO}

Objetivo: O objetivo desse trabalho foi analisar a percepção de estudantes sobre a utilização dos Exergames nas aulas de Educação Física, verificando nível de interesse e motivação, bem como discutir as implicações desse uso na prática docente. Metodologia: Participaram deste estudo 20 alunos dos anos finais do ensino fundamental em uma escola municipal da rede básica de ensino da cidade do Rio Grande. O questionário Long Flow State Scale Physical (FSS-2) foi utilizado para avaliar as questões relativas à percepção dos alunos a respeito dos Exergames. Além do questionário, foram produzidos diários de campo para registrar as potencialidades e dificuldades do uso de Exergames em sala de aula. Resultados e Discussão: Os alunos relataram um aumento no estímulo durante as aulas, mesmo que em algumas oportunidades a dinâmica possa ter comprometido a participação. Uma percepção positiva associada aos fatores motivacionais foi encontrada. Conclusão: A maioria dos itens das dimensões do fluxo demonstrou valores iguais ou acima de quatro, indicando que os indivíduos entraram em estado de fluxo.

Palavras-chave: Exergames. Tecnologias Digitais. Educação Física Escolar.

\footnotetext{
${ }^{1}$ Universidade Federal do Rio Grande, Instituto de Educação, Rio Grande - RS, Brasil.

2 Universidade Federal do Rio Grande, Faculdade de Educação Física, Rio Grande - RS, Brasil.

3 Universidade Federal de Pelotas, Escola Superior de Educação Física, Pelotas - RS, Brasil.
}

\section{Correspondência:}

Gustavo da Silva Freitas. Faculdade de Educação Física, Universidade Federal do Rio Grande, Av. Itália, $\mathrm{Km} \mathrm{8,} \mathrm{s/n,} \mathrm{Campus} \mathrm{Carreiros,} \mathrm{CEP} \mathrm{96201-900,} \mathrm{Rio} \mathrm{Grande} \mathrm{-} \mathrm{RS,} \mathrm{E-mail:}$ gsf78_ef@hotmail.com 


\section{"Is my turn to play"? The perceptions of the students about the use of the exergames in Physical Education classes}

\section{ABSTRACT}

Objective: The objective of this study was to analyze the students' perception about the use of Exergames in Physical Education classes, verifying level of interest and motivation, as well as discussing the implications of this use in teaching practice. Method: Twenty students from the final years of elementary school from a municipal school of the basic education of the city Rio Grande city, participated in this study. The Long Flow State Scale Physical (FSS-2) questionnaire was used to assess the questions regarding students' perceptions of Exergames. Besides the questionnaire, a field diaries were produced to record the potentialities and difficulties of using Exergames in the classroom. Results and discussion: Students reported an increase in stimulus during class, even though on some occasions the dynamics may have compromised participation. A positive perception associated with motivational factors was found. Conclusion: In addiction most of the items of the flow's dimensions showed values equal or above four, indicating that the individuals entered a flow state.

Keywords: School physical education. Pedagogic inovation. Education.

\section{¿"Ahora ES mi turno de jugar"? Percepción de Estudiantes sobre la utilización de Exergames em la Educación Fisica Escolar}

\section{RESUMEN}

Objetivo: El objetivo de este trabajo fue analizar la percepción de estudiantes sobre la utilización de los Exergames en las clases de Educación Física y para tanto, se buscó verificara el nivel de interés y motivación, así como discutir las implicaciones de ese uso en la práctica docente. Metodología: Participaron de este estudio 20 (veinti) alumnos de los años finales de la enseñanza fundamental en una escuela municipal de la red básica de enseñanza de la ciudad de Rio Grande. El cuestionario Long Flow State Scale Physical (FSS2) fue utilizado para evaluar las cuestiones relativas a la percepción de los alumnos acerca de los Exergames. Además del cuestionario, se produjeron diarios de campo para registrar las potencialidades y dificultades del uso de Exergames en el aula. Resultados y Discusión: Los alumnos reportaron un aumento en el estímulo durante las clases, aunque en algunas oportunidades la dinámica pudo haber comprometido la participación. Se encontró una percepción positiva asociada a los factores de motivación. Conclusión: La mayoría de los elementos de las dimensiones del flujo mostró valores igual o superior a cuatro, indicando que los individuos entraron en estado de flujo.

Palabras Clave: Exergames. Tecnologías Digitales. Educación Física Escolar. 


\section{INTRODUÇÃO}

Os avanços tecnológicos na sociedade contemporânea provocaram importantes transformações na existência e formas de socialização humana. Vivemos em tempos que as tecnologias digitais gerenciam o cotidiano, assumindo papeis significativos na condução das relações pessoais, no acesso à informação, no âmbito do trabalho, nas possibilidades de lazer, pois "a forma com que as pessoas agem e interagem (entre si e com o meio) é sempre modificada com a chegada de novidades tecnológicas" (EHRENBERG; SOUZA, 2012, p. 33).

Neste movimento, as Tecnologias Digitais de Informação e Comunicação (TDICs) ganharam força a partir da disseminação do computador e da internet. Com isso, as pessoas passaram a mudar a forma de se comunicarem entre si e de interagir com o mundo. Termos a impressão de que devemos estar sempre em "modo on", conectados o tempo todo. Bauman (2011) destaca que nossas conectividades interpessoais tendem cada vez mais a parecerem com as relações em redes sociais na internet. $\mathrm{O}$ que antes era lento, distante e fragmentado, hoje é rápido, próximo e integrado. Em outras palavras, como afirmam Santos e Santos (2014, p. 309), vivemos um tempo em que novas redes técnicas configuram "novas relações sociais, que acabam permitindo a circulação de ideias, mensagens, pessoas, mercadorias, num ritmo acelerado, criando interconexão entre os lugares de maneira sincrônica".

Segundo Turkle (1995), a cultura da simulação surge diante de modelos computacionais como seus representantes e os jogos digitais como seus elementos. Essas representações estabelecem uma lógica não linear que faz parte do universo de geração de screeners, termo utilizado por Rushkoff (1996) quando se referiu à geração nascida além da década de 80 , os quais interagem com telas de TV e videogame e demonstram uma diferenciada inteligência sensório-motora.

Justamente pela marca do desenvolvimento de uma cultura digital na contemporaneidade é que o uso das TDICs vem sendo estimulado no âmbito educacional. Segundo as Diretrizes Curriculares Nacionais para Formação Inicial e Continuada de Professores da Educação Básica (BRASIL, 2015) as tecnologias da informação e comunicação podem servir como ferramenta para aprimoramento da prática pedagógica usada e adaptada para enriquecer as aprendizagens, desenvolvendo a interatividade virtual de modo mais intenso e tornando possível o acesso dos estudantes à infraestrutura tecnológica.

Com o desenvolvimento das tecnologias digitais ampliam-se as possibilidades de interação em uma realidade virtual, que se caracteriza por ser uma experiência imersiva, interativa, estruturada e apresentada por meio de imagens gráficas geradas em tempo real por computador, que recria ao máximo 
a sensação de realidade para o indivíduo, ou seja, a realidade virtual permite a imersão completa em um ambiente simulado. Assim, é possível pensar em sua utilização como meio de ampliação das formas de ensino-aprendizagem, pois pode ser utilizada como uma forma de motivação dos alunos, e constitui-se como uma ferramenta educacional que proporciona diferentes experiências (BRAGA, 2001).

Nesta linha, destacam-se os Exergames (EXGs) que possibilitam a interação do movimento humano com a realidade virtual do videogame. Estes jogos exigem que o jogador execute movimentos que compreendam habilidades motoras e cognitivas (VAGHETTI; MUSTARO; BOTELHO, 2011), podendo assim, simular técnicas esportivas, de lutas ou danças, influindo diretamente a prática dessas modalidades na Educação Física (EF).

Na busca por inovação e seguindo a evolução tecnológica, estudos na esfera da educação vêm mostrando as interfaces entre a prática de atividade física e os EXGs, sobretudo como ferramenta de aprendizagem escolar. Estes estudos sugerem que, pela significativa presença dos games na cultura esportiva dos escolares, eles acabam por ser "um relevante mecanismo de socialização, diversão e aprendizagem" (ARAÚJO; FREITAS; CAMINHA; SILVA, 2011, p. 607); que quando jogados de "forma reflexiva e estratégica, incorporam bons princípios, capazes de dinamizar o ensino-aprendizagem às exigências da cibercultura" (BARACHO; GRIPP; LIMA, 2012, p. 122); "possibilitam um aumento no nível de atividade física" (VAGHETTI; BOTELHO, 2010, p. 9); além de salientar o "grande potencial de vivências emocionais e de criatividade nas propostas" (SCHWARTZ et al., 2013, p.1).

Este trabalho, portanto, se insere neste cenário de forma a trazer mais elementos que avaliem as potencialidades dos EXGs na Educação Física Escolar. Para tanto, teve por objetivo analisar a percepção de estudantes dos Anos Finais do Ensino Fundamental sobre a utilização dos EXGs nas aulas de EF, verificando o nível de interesse e a motivação, bem como discutir as implicações desse uso na prática docente.

\section{MÉTODO}

Este estudo possui características de uma pesquisa descritiva que, segundo Gil (2002) tem por objetivo descrever as características de determinada população e/ou fenômenos. De caráter quali-quantitativo, seguiu tanto por método de intervenções e análise estatística quanto por produção de registros apreciativos de informações. A combinação destes métodos visou maximizar a quantidade de dados incorporados ao desenho da pesquisa, aprimorando as conclusões do trabalho pelo ato da confirmação e/ou da complementariedade 
(PARANHOS et al., 2016).

Os equipamentos utilizados para as intervenções foram um videogame da marca Xbox $360^{\circledR}$, um projetor multimídia, um aparelho de som e os games Kinect Sports Ultimate Collection e Just Dance 2017. Estes games foram escolhidos na intenção de proporcionar acesso a esportes menos tradicionais como esqui na neve, tênis, vôlei de praia, boxe, práticas corporais pouco abordadas nas aulas de Educação Física (DINIZ; DARIDO, 2012), e pela dança ser considerada um dos temas da cultura corporal cujo conteúdo também faz parte do universo da Educação Física (COLETIVO DE AUTORES, 1992).

Duas intervenções foram realizadas entre os meses de agosto e setembro de 2018, cada qual com duração de 1 hora e 30 minutos, durante as aulas de EF de uma turma do $8^{\circ}$ ano, em uma escola municipal da rede básica de ensino do município de Rio Grande/RS. Após a aprovação no Comitê de Ética em Pesquisa da Universidade Federal de Pelotas (CAEE: 2.985.360/2018), foram convidados a participar da pesquisa 24 alunos. A escolha da turma se deu alinhada à disciplina de Estágio Supervisionado $\mathrm{III}^{4}$, nos Anos Finais do Ensino Fundamental, ocorrida no primeiro semestre de 2018.

Para a produção dos dados foi aplicado um questionário para avaliar as questões relativas à percepção dos alunos a respeito dos EXGs nas aulas de EF. Este questionário é baseado no conceito da Theory of Flow, ou Teoria do Fluxo, desenvolvida por Csikszentmihalyi (1992, 1999), o qual afirma que determinadas atividades podem ser intrinsecamente motivantes devido ao alto grau de prazer que proporcionam em sua realização e, por isso, levam o indivíduo a um estado de profundo envolvimento e sentimento intenso de alegria e satisfação pessoal. $\mathrm{O}$ instrumento auto aplicado foi direcionado aos alunos que participaram de, pelo menos 50\%, das intervenções - correspondente a 20 alunos - tendo sido entregue ao final da segunda intervenção para preenchimento e devolução imediata 5 .

O questionário Long Flow State Physical (FSS-2) (JACKSON; EKLUND; MARTIN, 2010), consiste de 36 questões em que as respostas são dadas numa escala tipo Likert de cinco pontos ( 1 = discordo totalmente; 2 = discordo; $3=$ nem concordo nem discordo; 4 = concordo; 5 = concordo totalmente). O FSS-2 foi desenvolvido para a utilização imediatamente após uma atividade que envolve movimento humano. $O$ instrumento de língua inglesa ainda não foi validado para a língua portuguesa e, até o fechamento desta pesquisa, ainda não foram

\footnotetext{
${ }^{4}$ Disciplina localizada no 70 semestre do Curso de Licenciatura em Educação Física da Universidade Federal do Rio Grande/RS que tem por ementa: "Estudos, proposição e experimentação de práticas profissionais, com ênfase nas vivências supervisionadas nos quatro últimos anos do Ensino Fundamental" (PPC CURSO DE LICENCIATURA EM EDUCAÇÃO FÍSICA, 2005).

${ }^{5}$ Além do preenchimento do questionário, os participantes entregaram o Termo de Consentimento Livre e Esclarecido associado ao projeto aprovado no Comitê de Ética.
} 
encontrados estudos relacionados à validação do instrumento de pesquisa para este idioma. Entretanto, justifica-se a escolha do questionário pela frequência com que é citado na área de games. O questionário foi traduzido pelo Instituto de Letras da Universidade Federal do Rio Grande (ILA/FURG), através do Projeto de Apoio a Pesquisa Científica Discente (PAPCD). Foi realizado também um backtranslation, no qual é feita uma versão do instrumento novamente para o idioma inglês a fim de verificar possíveis problemas em função das diferenças culturais entre as línguas.

Além do questionário, foram produzidos cinco diários de campo com descrições e percepções produzidas durante os dias de preparação e intervenção antes e depois das aulas. Neles foram detalhados também os acontecimentos no período que antecedeu o início das intervenções, considerando-o já como imersão do pesquisador no campo. É o diário de campo que permite descrever e analisar o fenômeno estudado, além de mostrar a ligação entre as diversas hipóteses levantadas pelo pesquisador, bem como refletir e compreender todas as etapas da pesquisa (WEBER, 2009).

Para a análise de dados quantitativos foi empregada uma estatística descritiva para se determinar a média dos valores de fluxo, que segundo Jackson, Eklund e Martin (2010), os autores do The Flow Manual, valores iguais ou acima de quatro podem ser considerados como um estado de fluxo, intrinsecamente motivante. Já as informações constantes dos diários de campo foram consideradas a partir da atividade docente enquanto categoria de análise.

\section{Resultados E Discussão}

O período preparatório às intervenções deu sinais de que a proposta de tornar os EXGs como recurso pedagógico nas aulas de EF tem reflexos na organização do trabalho docente. Isto porque esse uso depende previamente de acesso a uma quantidade significativa de equipamentos que a escola nem sempre dispõe; exige a testagem anterior à utilização para familiarização e minimização de erros; bem como a disponibilidade de um espaço na instituição com determinadas características adequadas à vivência plena do jogo (tamanho amplo, com baixa iluminação, número suficiente de tomadas, presença de tela ou televisão de grande proporção). Estes aspectos exigem um tempo de dedicação extraclasse por parte do professor que precisa ser sincronizado às demais demandas de sua jornada de trabalho e vida pessoal.

Alguns obstáculos surgiram no momento de obter os equipamentos junto à instituição de ensino superior devido aos trâmites de empréstimo serem complexos. Assim, outros métodos de aquisição dos equipamentos (Xbox 360 e jogos) foram utilizados, baseados no empréstimo por parte de pessoas do círculo 
de amizade. Em seguida, houve a necessidade de cumprir uma fase de familiarização com os jogos e planejamento da melhor forma de aplicá-los na escola. Ainda assim, ao realizar a testagem na véspera da primeira intervenção e fazer um mapeamento das condições da sala, alguns contratempos foram identificados:

[...] disponibilizei um dia para ir até a escola e testar tudo lá, e assim verifiquei a necessidade de levar uma extensão para conectar o Xbox e a caixa de som, além de um cabo adaptador especial para conectar o som ao projetor (DIÁRIO DE CAMPO, 30/08/18).

Além disso, é preciso ressaltar que, questões como a falta de conhecimento tecnológico, ausência de recurso financeiro, preparação e vontade de inovação dos professores e o preconceito com os videogames por serem vistos como algo voltado apenas para o entretenimento, e não como algo educativo, podem ser obstáculos para a implementação desta ferramenta dentro das escolas.

Entretanto, a proposta dos EXGs valida-se de modo que a utilização das Tecnologias Digitais vem transformando o processo educacional que, segundo Tapscott (2010), passou de uma abordagem focada no professor para um modelo focado no estudante e baseado na colaboração. Visto a naturalidade com que esta geração usufrui das tecnologias digitais, isso faz com que os ambientes escolares sejam habitados por alunos mais interativos e conectados (MACHADO, 2016). Como observado em determinado momento da primeira intervenção, quando a proposta dos EXGs foi revelada para a turma foi possível perceber toda essa familiaridade com a tecnologia:

[...] eles começaram a se agitar, notei uma empolgação neles. Um aluno falou: 'realidade virtual professor?' e eu falei que sim, e alguns outros falaram que tinham Xbox em casa (DIÁRIO DE CAMPO, $31 / 08 / 18)$.

Uma questão que exigia certos cuidados na organização da atividade e que se impõe a refletir é sobre a relação entre o número de alunos diretamente envolvidos com a prática versus àqueles que, mesmo momentaneamente, assumem o lugar de espectadores. Isto porque, existe um limite de jogadores que o equipamento permite atuar ao mesmo tempo, cabendo ao restante assistir e aguardar o seu momento. Um dos games utilizado nesta pesquisa, o Just Dance no Xbox 360, permitiu que quatro alunos jogassem ao mesmo tempo, porém verificou-se após as intervenções que o mesmo game no Xbox ONE, em uma versão mais nova do mesmo console, permite até seis jogadores.

O desafio de envolver uma turma com 24 alunos pôde ser trabalhado a partir da característica inovadora de tornar as tecnologias digitais algo cada vez mais ordinário na vida de crianças e jovens, um aliado no aprendizado lúdico de práticas que, provavelmente, nunca tiveram a possibilidade de vivenciar por falta 
de estrutura e materiais na instituição, ou mesmo por alguma dificuldade de acesso econômico ou cultural. No entanto, a preocupação com a ordenação e na manutenção de uma mobilização de todos foi minimizada:

[...] fiquei surpreso, pois ao entrar na sala todos os alunos já se posicionaram em volta da sala e sentados nas cadeiras. Assim expliquei que seriam dois alunos por vez jogando. Ao começar, todos os alunos em volta gritavam animados, torcendo para um ou outro aluno ganhar, e rindo de alguns movimentos engraçados que aconteciam. Ao acompanhar a atividade alguns alunos vinham até mim dizendo: posso ir eu e ele depois, professor? Muito empolgados (DIÁRIO DE CAMPO. 31/08/18).

Desse modo, a auto-organização por parte dos alunos contribuiu para que a atividade transcorresse de forma mais dinâmica e sistematizada, evitando problemas de dispersão ou confusão diante da atividade proposta. Esse fator pode ser explicado pela faixa etária da turma e pela minha familiaridade com os alunos, o que facilitou no desenvolvimento da intervenção. Vieira et al. (2014) também identificaram o mesmo comportamento dos alunos em uma intervenção com EXGs em uma outra escola pública municipal da mesma cidade.

Apesar da mobilização e envolvimento da turma, a situação de exposição perante a todos os colegas, centralizando olhares e, assim, causando uma intimidação e/ou inibição, e ainda, o fato de se achar incapaz para realizar algum tipo de movimento, foram motivos de resistência por parte de uma aluna:

Apesar disso, a atividade não contemplou $100 \%$ dos alunos, pois uma aluna, mesmo com uma certa insistência minha, não quis participar e ficou apenas olhando os seus colegas jogarem (DIÁRIO DE CAMPO, 31/08/18).

Ao ser indagada sobre o porquê não participar, ela respondeu que:

[...] sentia vergonha, pois todos estariam vendo-a jogar e que ela não tinha habilidades com dança e esportes (DIÁRIO DE CAMPO, 14/09/18).

Este episódio deve ser interpretado em um contexto de experiências anteriores que causaram um impacto desconfortável sobre a percepção dessa aluna com as aulas de EF. Ainda que, geralmente, os escolares demonstrem gostar das aulas de EF, é importante ressaltar que diversos fatores levam o estudante a um grau de desmotivação, como as diferenças individuais ou atividades muitas vezes repetitivas (KROUSCAS, 1999; STELZER et al.,2004). Entretanto, levando isso em consideração, notou-se um maior entusiasmo, disposição e interesse dos alunos, reforçando a percepção positiva com os EXGs, tanto que: 
[...] os alunos mais tímidos e que participavam pouco das minhas aulas de estágio, eram os mais empolgados, pois se não tinham tanta habilidade para praticar esportes, ali naquele momento, eles poderiam jogar vários esportes com sucesso, e serem bons tanto quanto qualquer um. Eles estavam gostando tanto que perguntaram se a próxima aula seria assim também (DIÁRIO DE CAMPO, $31 / 08 / 18)$.

Segundo Manley e Whitaker (2011), esta percepção positiva está ligada a fatores motivacionais, destacando que abordagens de ensino inovadoras podem aumentar o entusiasmo dos estudantes pelas aulas. Com isso, o uso das novas tecnologias contribui ou provoca mudanças na forma de socializar e interagir com outras pessoas, bem como no modo de colaborar e compartilhar informações, influenciando nos processos de aprendizagem. Segundo Rodrigues (2006), devese aproveitar do alto poder atrativo dos jogos nos jovens para tornar a aprendizagem algo mais prazeroso e recompensador.

Neste caminho, se mostra interessante levar o jogo como um método eficaz de aprendizagem através do lúdico. Desta forma, os EXGs buscam tirar o aluno do estado de inatividade e levá-lo a interagir de forma física e muito mais dinâmica com os jogos eletrônicos (SILVERA; TORRES, 2007). Isso ficou evidenciado quando os alunos jogaram vôlei de praia, pois:

[...] os alunos precisavam fazer movimentos como sacar, passar, descer até o chão para pegar uma bola e pular para atacar e bloquear. Com isso, percebi que muitos cansavam durante a partida, teve até um aluno que pediu substituição, pois cansou de tanto pular (DIÁRIO DE CAMPO, 31/08/18).

Além disso, os EXGs podem auxiliar no desenvolvimento da aprendizagem dos movimentos com possíveis transferências para o jogo no ambiente real, pois a chance de sucesso no movimento é proporcional a experiência contínua dos jogadores, ou seja, uma maior eficácia do movimento está atrelada com o uso contínuo do jogo (MOITA, 2007). Corroborando com esse fato, Franco, Lima e Vaghetti (2018) verificaram uma transferência de aprendizagem positiva após uma intervenção com o game Kinect Sports, os alunos que realizaram o treinamento na modalidade table tennis (tênis de mesa), tiveram os resultados significativamente superiores ao grupo que não realizou o treinamento virtual.

Neste contexto, os alunos relataram que se sentiram bem realizando as atividades e que, como mencionado por um aluno:

[...] não tinha tido uma aula de educação física tão diferente e divertida como essa (DIÁRIO DE CAMPO, 31/08/18). 
Isso não impediu que, durante a segunda intervenção, fosse evidenciada uma situação muito comum em aulas de EF escolar, ou seja, pedidos de alguns meninos para jogar futebol na quadra. Neste caso, estas tentativas vieram como forma de ocupar o tempo enquanto esperavam sua vez para voltar aos EXGs. Neste caso, uma possibilidade de intervenção com EXG é a sua utilização com os elementos reais, ou seja, o professor pode trabalhar os fundamentos de determinado esporte de maneira virtual e não virtual, no EXG e no pátio, como foi trabalhado na pesquisa de Vieira et al. (2014).

Ao analisar essa situação, pode-se levantar algumas hipóteses acerca do fato ocorrido. Primeiro que, com a prática do "largobol" que se caracteriza por não apresentar grandes pretensões no trabalho docente, cujo objetivo principal seria ocupar o tempo dos alunos com alguma atividade (GONZÁLEZ; FENSTERSEIFER, 2006; MACHADO et al., 2010), existe a cultura da associação entre EF e futebol, em que, independentemente da atividade que está sendo feita pelo professor, os alunos sempre expectam por este esporte.

[...] Talvez a situação de ficarem esperando sua vez para jogarem os jogos seja um motivo, visto que querem usar da aula de EF para estarem a todo momento correndo e praticando alguma atividade física ativamente (DIÁRIO DE CAMPO, 14/09/18).

Sobre a criação de expectativas, Frago (1995) ressalta que a cultura escolar estabelecida está impregnada de hábitos, valores e rituais que tendem a se perpetuar no tempo. Assim, as mudanças necessárias acontecem em processos vagarosos, cujo professor precisa compreender esses códigos para poder desenvolver seu trabalho. Entretanto, o uso dos EXGs entra na lógica de tornar nova a EF, com uma necessidade de inovação nas aulas, em que o professor precisa estar receptivo a este novo conhecimento e aprendizado, acompanhando os avanços tecnológicos, assim como faz a sociedade.

Em definição, Fensterseifer e Silva (2011) apontam que uma prática inovadora é aquela que procura materializar, na intervenção, a proposta da cultura corporal de movimento. Portanto, é importante pensar novas práticas para romper com uma determinada compreensão da EF que tem resistido a transformações. Desse modo, é possível caracterizar uma nova EF a partir de elementos que busquem introduzir novas práticas e reinventar as tradicionais, um ensino que vá além dos modelos padronizados de movimento, e do entendimento da EF como uma verdadeira disciplina (ALMEIDA, 2017).

Segundo Vaghetti (2013), a experiência subjetiva denominada "fluxo" pode ser descrita em um conjunto de nove dimensões, em que a combinação de todos esses elementos provoca um sentimento de profundo envolvimento com a atividade. São elas: 
Quadro 1 - Caracterização das dimensões do fluxo

\begin{tabular}{|c|c|}
\hline DIMENSÃO & CARACTERIZAÇÃO \\
\hline $\begin{array}{c}\text { EQUILÍBRIO } \\
\text { DESAFIO/HABILIDADE }\end{array}$ & $\begin{array}{l}\text { A experiência usualmente ocorre quando a pessoa se } \\
\text { confronta com tarefas que têm a chance de completar. }\end{array}$ \\
\hline $\begin{array}{l}\text { CONCENTRAÇÃO NA } \\
\text { TAREFA }\end{array}$ & $\begin{array}{l}\text { A pessoa deve ser capaz de se concentrar no que está } \\
\text { fazendo. }\end{array}$ \\
\hline METAS CLARAS & $\begin{array}{l}\text { A concentração geralmente é possível porque a tarefa em } \\
\text { questão possui metas claras. }\end{array}$ \\
\hline $\begin{array}{l}\text { O FEEDBACK IMEDIATO } \\
\text { E INEQUÍVOCO }\end{array}$ & $\begin{array}{l}\text { O feedback é claro, imediato e sem ambiguidades durante } \\
\text { a realização da tarefa. }\end{array}$ \\
\hline $\begin{array}{l}\text { CONCENTRAÇÃO } \\
\text { INTENSA NA TAREFA }\end{array}$ & $\begin{array}{l}\text { A pessoa age com profundo envolvimento, mas com a } \\
\text { aparente sensação de ausência de esforço, o que remove } \\
\text { da consciência preocupações e frustrações da vida } \\
\text { cotidiana. }\end{array}$ \\
\hline SENSO DE CONTROLE & $\begin{array}{l}\text { Experiências envolventes permitem que as pessoas } \\
\text { exercitem o senso de controle sobre suas ações. }\end{array}$ \\
\hline $\begin{array}{l}\text { AUSÊNCIA DE } \\
\text { PREOCUPAÇÃO COM O } \\
\text { SELF }\end{array}$ & $\begin{array}{l}\text { A preocupação com o self desaparece, paradoxalmente; } \\
\text { porém, o sentido do self emerge mais forte depois da } \\
\text { finalização da experiência de fluxo. }\end{array}$ \\
\hline $\begin{array}{c}\text { TRANSFORMAÇÃO DO } \\
\text { TEMPO }\end{array}$ & $\begin{array}{l}\text { O sentido de duração do tempo é alterado: as horas } \\
\text { passam como se fossem minutos e os minutos podem se } \\
\text { ampliar e parecerem horas. }\end{array}$ \\
\hline $\begin{array}{l}\text { EXPERIÊNCIA } \\
\text { AUTOTÉLICA }\end{array}$ & $\begin{array}{l}\text { Experiência autotélica, cujas atividades são realizadas por } \\
\text { prazer e diversão, sem expectativa de recompensa. }\end{array}$ \\
\hline
\end{tabular}

Na tabela a seguir podem ser vistos os valores parciais do fluxo para cada uma de suas dimensões.

Tabela 1 - Dimensões do fluxo e seus respectivos valores

\begin{tabular}{l|c}
\hline Dimensões do fluxo & Valores Médios de Fluxo \\
\hline 1. Equilíbrio habilidade - desafio & 4.11 \\
2. Fusão ação e consciência & 4.25 \\
3. Metas claras & 4.60 \\
4. Feedback inequívoco & 4.38 \\
5. Concentração na tarefa & 4.25 \\
6. Senso de controle & 4.26 \\
7. Ausência de preocupação com self & 3.83 \\
8. Transformação do tempo & 3.86 \\
9. Experiência autotélica & 4.57 \\
\multicolumn{1}{c}{ Média total } & 34.04 \\
\hline
\end{tabular}

Valores $\geq 4$ representam estado de fluxo.

Analisando os dados contidos na Tabela 1 é possível observar que apenas 
dois itens apresentaram valores iguais ou menores a quatro, especificamente "ausência de preocupação com self" (3.83) e "transformação do tempo" (3.86), indicando que os indivíduos não entraram em estado de fluxo.

É importante ressaltar o resultado da dimensão "ausência de preocupação com self" (3.83), pois quando a atividade é envolvente, o indivíduo esquece as distrações e passa a não se preocupar com o seu próprio eu, o self (CSIKSZENTMIHALYI, 1992). No entanto, foi possível perceber que os alunos, até por estarem em uma fase da vida em que o chamado bullying escolar é crescente, expressaram algum nível de vergonha ou timidez, demonstrando preocupação com o que os colegas de turma iriam manifestar, afetando assim o desempenho em determinada atividade. No ambiente escolar, segundo Zequinão et al. (2016), a sala de aula é o espaço de maior incidência das agressões feitas tanto por meninos quanto por meninas, muito porque é o local onde passam a maior parte do tempo na instituição, vindo a Educação Física em terceiro lugar.

Sobre o item "transformação do tempo" (3.86), não houve estado de fluxo, possivelmente pela rotatividade de jogadores, o que fazia com que o tempo de espera chegasse a ser maior do que o período de jogo. Há chances das respostas terem sido atravessadas pela sensação de alguns alunos de que não pode haver tempo ocioso nas aulas de Educação Física, demandando um "estar em movimento" a todo instante como "contraponto a um ensino pautado por preocupações conteudistas, de ensino verbointelectual e de relações pedagógicas marcadas por vivências formais, frias, silenciosas" (GARIGLIO, 2010, p. 179).

Por outro lado, a maioria dos itens das dimensões do fluxo (sete) demonstraram valores iguais ou acima de quatro: "equilíbrio habilidade - desafio" (4.11), "fusão ação e consciência" (4.25), "metas claras" (4.60), "feedback inequívoco" (4.38), "concentração na tarefa" (4.25), "senso de controle" (4.26) e "experiência autotélica" (4.57), indicando que os indivíduos entraram em estado de fluxo. Destaque para a maior prospecção do item "experiência autotélica" (4.57), em que a motivação para realizar a tarefa é intrínseca, ou seja, os alunos não tinham expectativa de recompensa, realizaram as atividades pelo simples prazer e diversão.

Outro aspecto interessante é que o maior valor se relaciona a dimensão "metas claras" (4.60). Neste caso o videogame pode ser mais ou menos complexo do ponto de vista cognitivo para o entendimento do gameplay. Os EXGs utilizados nesta pesquisa apresentaram objetivos claros e bem definidos, o que segundo Csikszentmihalyi (1990) contribui para que o indivíduo possa se envolver rapidamente.

Nesta pesquisa, os valores do fluxo se apresentaram bastante elevados, o que evidencia o alto grau de motivação intrínseca na qual os alunos apresentaram diante da atividade. Além disso, os resultados se relacionam com os dados 
descritos nos diários de campo. Assim, com base nos resultados é possível identificar que, com a atividade proposta, houve uma maior motivação e envolvimento dos alunos se comparado às aulas de estágio supervisionado realizadas com essa mesma turma anteriormente, no qual esses aspectos são significativos para os processos de ensino e de aprendizagem.

\section{CONSIDERAÇÕES FINAIS}

Através dos resultados, é possível concluir que os EXGs podem ser usados como uma nova ferramenta de apoio nas aulas de EF e uma alternativa para os alunos desmotivados. Essa maior percepção positiva, que os alunos tiveram com as intervenções, faz com que aumentem as possibilidades de vivências de conteúdos, seja nos esportes, lutas ou danças.

Entretanto, é preciso considerar a viabilidade desta ferramenta, entendendo o contexto e a realidade nos quais a escola está inserida. Não há como negar a existência de desigualdades tecnológicas entre as instituições de ensino na educação básica. Assim, considerar a inserção desta tecnologia digital em todos os níveis escolares prescinde de suporte para tal e que desde a alfabetização o professor incorpore esta cultura na sua prática docente, seja usando jogos para o processo de ensino-aprendizagem ou lendo e escrevendo em dispositivos digitais. Implica, além de tudo, saber que crianças que já nasceram incluídas numa cultura digital passam a pensar e agir com esses dispositivos, fomentando toda uma cultura digital para a escola.

Por fim, é importante também que haja uma formação e planejamento prévio do professor para implementação dos EXGs nas aulas a fim de que não transforme esta utilização em atividades isoladas, mas ao contrário conectadas a uma composição curricular. Os estudos sobre EXGs são recentes, por isso requerem continuidade das pesquisas que avaliem as travas e os avanços de seu uso no ambiente escolar.

\section{REFERÊNCIAS}

ALMEIDA, Felipe Quintão. Educação física escolar e práticas pedagógicas inovadoras: uma revisão. Corpoconciência, v. 21, n. 3, p. 7-16, 2017. Disponível em: http://periodicoscientificos.ufmt.br/ojs/index.php/corpoconsciencia/article/view/5312.

ARAÚJO, Bruno Medeiros Roldão de; FREITAS, Clara Maria Silvestre Monteiro de; CAMINHA, Iraquitan de Oliveira; SILVA, Priscilla Pinto Costa da. Virtualização esportiva e os novos paradigmas para o movimento humano. Motriz, v. 17, n. 4, p. 600-609, 2011. Disponível em: http://www.scielo.br/scielo.php?script=sci arttext\&pid=S198065742011000400004. 
BARACHO, Ana Flávia de Oliveira; GRIPP, Fernando Joaquim; LIMA, Márcio Roberto de. Os exergames e a educação física escolar na cultura digital. Revista Brasileira de Ciências do Esporte, v. 34, n. 1, p. 111-126, 2012. Disponível em:

http://www.scielo.br/scielo.php?script=sci arttext\&pid=S0101-32892012000100009.

BAUMAN, Zigmund. 44 Cartas do Mundo Líquido Moderno. Rio de Janeiro: Zahar, 2011.

BRAGA, Mariluci. Realidade virtual e educação. Revista de Biologia e Ciências da Terra, Paraíba, v. 1, n. 1, 2001. Disponível em:

http://joaootavio.com.br/bioterra/workspace/uploads/artigos/realidadevirtual5155c805d3801.pdf.

BRASIL. Diretrizes Curriculares Nacionais para Formação Inicial e Continuada de Professores para Educação Básica. Brasília: MEC/SEB/DICEI, 2015.

COLETIVO DE AUTORES. Metodologia do Ensino da Educação Física. São Paulo: Cortez, 1992.

CSIKSZENTMIHALYI, Mihaly. A descoberta do fluxo: a psicologia do envolvimento com a vida cotidiana. São Paulo: Rocco, 1999.

CSIKSZENTMIHALYI, Mihaly. A Psicologia da felicidade. São Paulo: Saraiva, 1992.

CSIKSZENTMIHALYI, Mihaly. Flow: the Psychology of Optimal Experience. New York: Harper Perennial, 1990.

DINIZ, Irlla Karla dos Santos; K. S.; DARIDO, Suraya Cristina. Livro didático: uma ferramenta possível de trabalho com a dança na Educação Física Escolar. Motriz, v. 18, n. 1, p. 176-185, 2012. Disponível em: http://www.scielo.br/scielo.php?pid=S1980$65742012000100018 \&$ script $=$ sci abstract\&tlng=pt.

EHRENBERG, Karla Caldas; SOUZA, Rogério Furlan. Comunicação mercadológica em mídias digitais e o consumidor internauta. Acta Científica, v. 21, n. 2, p. 33-44, 2012. Disponível em: http://revistas.unasp.edu.br/actacientifica/article/view/363.

FENSTERSEIFER, Paulo Evaldo; SILVA, Marlon André da. Ensaiando o "novo" em educação física escolar: a perspectiva de seus atores. Revista brasileira de ciências do esporte, v. 33, n. 1, p. 119-134, 2011. Disponível em:

http://revista.cbce.org.br/index.php/RBCE/article/view/874.

FRAGO, Antonio Viñao. Historia de La educación e historia cultural - posibilidades, problemas, cuestiones. Revista Brasileira de Educação, São Paulo, n. 0, p. 63-82, 1995. Disponível em: http://educacao.uniso.br/pseletivo/docs/FRAGO.pdf.

FRANCO, Vagner Eduardo Hirschfeld; LIMA, Marcos Jordânio Feitosa; VAGHETTI, Cesar Augusto Otero. O. Exergames como ferramenta para aprendizagem motora. In: Anais Congresso de Iniciação Científica UFPEL, 2018.

GARIGLIO, José Ângelo. Modelos de ação profissional de professores de Educação Física de uma escola profissionalizante. Movimento. v. 16, n. 2, p. 167-191, 2010. Disponível em: https://seer.ufrgs.br/Movimento/article/view/8711.

GIL, Antonio Carlos. Como elaborar projetos de pesquisa. 4. ed. São Paulo: Atlas, 2002.

GONZÁLEZ, Fernando. Jaime; FENSTERSEIFER, Paulo Evaldo. Educação física e cultura escolar: critérios para identificação do abandono do trabalho docente. In: Congreso de 
Educación Física: Repensando la Educación Física, 2006, Córdoba. Actas del Congreso de Educación Física: repensando la Educación Física. Córdoba: Ipef, p. 734 -746, 2006.

JACKSON, Sue; EKLUND, Bob; MARTIN, Andrew. The flow scales manual. Queensland: Mind Garden, 2010.

KROUSCAS, James Athan Jr. Middle school students' attitudes toward a physical education program. 1999. Tese (Doutorado) - Programa de Pós-Graduação do Departamento de Ensino e Aprendizagem, do Instituto Politécnico e Universidade Estadual de Virgínia, Blacksburg, 1999.

MACHADO, Silvia Cota. Análise sobre o uso das tecnologias digitais da informação e comunicação (TDICs) no processo educacional da geração internet. Revista Novas Tecnologias na Educação, v. 14, n. 2, 2016. Disponível em: https://seer.ufrgs.br/renote/article/view/70645.

MACHADO, Thiago da Silva; BRACHT, Valter; FARIA, Bruno de Almeida; MORAES, Claudia, ALMEIDA, Ueberson; ALMEIDA, Felipe Quintão. As práticas de desinvestimento pedagógico na educação física escolar. Movimento, v. 16, n. 2, p. 129-147, 2010. Disponível em: https://seer.ufrgs.br/Movimento/article/view/10495.

MANLEY, Andrew; WHITAKER, Lisa. Wii-learning: using active video games to enhance the learning experience of undergraduate sport psychology students. Sport \& Exercise Psychology Review, London, v. 7, n. 2, p. 45-55, 2011. Disponível em: https://www.semanticscholar.org/paper/Wii-learning\%3A-Using-Active-Video-Games-toenhance-Manley-Whitaker/973f7df3676ab62a1a538644f7ab60690bbc9175.

MOITA, Filomena Maria. Game on: jogos eletrônicos na escola e na vida da geração. Campinas: SP. Alínea. 2007.

PARANHOS, Ranulfo; FILHO, Dalson Britto Figueiredo; ROCHA, Enivaldo Carvalho da; JÚNIOR, José Alexandre da Silva; FREITAS, Diego. Uma introdução aos métodos mistos. Sociologias [online], v. 18, n. 42, p. 384-411, 2016. Disponível em:

http://www.scielo.br/scielo.php?pid=S1517-

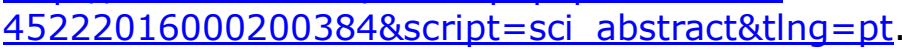

PROJETO PEDAGÓGICO. Curso de Licenciatura em Educação Física - Universidade Federal do Rio Grande, 2005.

RODRIGUES, Gustavo Dore. Jogos Eletrônicos na sala de aula: possibilidades de ensino através do lúdico e do digital. In: XXIX Congresso Brasileiro de Ciências da Comunicação UnB. Brasília, 2006, Brasília. Anais do XXIX Congresso Brasileiro de Ciências da Comunicação UnB, 2006.

RUSHKOFF, Douglas. Playing the Future: How Kids' Culture Can Teach Us to Thrive in an Age of Chaos. New York, NY: HarperCollins Publishers, 1996.

SANTOS, Valmaria Lemos da Costa; SANTOS, José Erimar dos. As redes sociais digitais e sua influência na sociedade e educação contemporâneas. Holos, ano 30, v. 6, p. 307328, 2014. Disponível em:

http://www2.ifrn.edu.br/ojs/index.php/HOLOS/article/view/1936.

SCHWARTZ, Gisele. Maria; SANTIAGO, Danilo Roberto Pereira; KAWAGUTI, Cristiane Naomi; TAVARES, Gisele Hellena; FIGUEIREDO, Juliana de Paula; PALHARES, Marcelo Fadori Soares; NASCIMENTO, Amanda Mayara. Apropriação das tecnologias virtuais como estratégias de intervenção no campo do lazer: os webgames adaptados. Licere, v. 16, n. 3, p. 1-26, 2013. Disponível em: http://cev.org.br/biblioteca/apropriacao-das- 
tecnologias-virtuais-como-estrategias-intervencao-campo-lazer-os-webgamesadaptados-1/.

SILVERA, Guilherme Carvalho Franco; TORRES, Livia Maria Zahra Barud. Educação física escolar: um olhar sobre os jogos eletrônicos. Belo Horizonte: XV Congresso Brasileiro de Ciências do Esporte, 2007.

STELZER, Jiri; ERNEST, James; FENSTER, Mark; LANGFORD, George. Attitudes toward physical education: a study of high school students from four countries: Austria, Czech Republic, England and USA. College Student Journal, Birmingham, v. 38, n. 2, p. 171178, 2004. Disponível em:

https://www.researchgate.net/publication/291021679 Attitudes toward physical educat ion A study of high school students from four countries -

Austria Czech Republic England and USA.

TAPSCOTT, Don. A hora da geração digital. Rio de Janeiro: Nova Fronteira, 2010.

TURKLE, Sherry. Life on the Screen: Identity in the Age of the Internet. New York, NY: Touchstone, 1995.

VAGHETTI, Cesar Augusto Otero. Exergames em rede: a Educação Física no Cyberspace. 2013. Tese (Doutorado em Educação em Ciências: Química da Vida e Saúde) Universidade Federal do Rio Grande, 2013.

VAGHETTI, Cesar Augusto Otero; BOTELHO, Silvia Silva da Costa. Ambientes virtuais de aprendizagem na Educação Física: uma revisão sobre a utilização de exergames. Ciências \& Cognição, v. 15, n. 1, p. 76-88, 2010. Disponível em:

http://www.cienciasecognicao.org/revista/index.php/cec/article/view/292.

VAGHETTI, Cesar Augusto Otero; MUSTARO, Pollyana Notargiacomo; BOTELHO, Silvia Silva da Costa. Exergames no ciberespaço: uma possibilidade para educação física. In: Simpósio Brasileiro de Games e Entretenimento Digital, 10, Salvador. Anais do Simpósio Brasileiro de Games e Entretenimento, 2011.

VIEIRA, Karina Langone; VAGHETTI, Cesar Augusto Otero; MAZZA, Sheynara Emi Ito Mazza; CORRÊA, Leandro Quadro. Características comportamentais de escolares e sua percepção sobre a utilização dos exergames nas aulas de educação física. Cinergis, v. 15, n. 2, p. 65-69, 2014. Disponível em:

https://online.unisc.br/seer/index.php/cinergis/article/view/4431.

WEBER, Florence. A. Entrevista, a pesquisa e o íntimo, ou: por que censurar seu diário de campo? Horizontes Antropológicos, v. 15, n. 32, p. 157-170, 2009. Disponível em: http://www.scielo.br/scielo.php?script=sci arttext\&pid=S0104-71832009000200007.

ZEQUINÃO, Marcela Almeida; MEDEIROS, Pâmella de; PEREIRA, Beatriz; CARDOSO, Fernando Luis. School bullying: A multifaceted phenomenon. Educação e Pesquisa. [online], v. 42, n. 1, p. 181-198, 2016. Disponível em:

http://www.scielo.br/scielo.php?pid=S1517-

97022016000100181\&script=sci arttext\&tIng=en. 